\title{
Produção e Divulgação de Conhecimentos Científicos em Tempos de Pandemia da COVID-19
}

\author{
Production and Dissemination of Scientific Knowledge in Times of the COVID-19 Pandemic
}

\author{
Producción y Difusión de Conocimiento Científico en Tiempos de la Pandemia COVID-19
}

Promover a difusão de pesquisas relacionadas ao mundo do trabalho é a missão precípua da Revista Psicologia: Organizações e Trabalho (rPOT). Nessa direção, a expectativa é de contribuir para o processo de construção, aperfeiçoamento e transmissão de conhecimentos científicos e recursos técnicos úteis à comunidade.

A rPOT tem reconhecimento científico e social, entre pesquisadores, estudantes e profissionais da Psicologia das Organizações e do Trabalho, e áreas afins. Reflete o esforço empreendido por seu corpo de editores e pareceristas em divulgar achados científicos, o desenvolvimento e o aperfeiçoamento de teorias, métodos e tecnologias, assim como promover a reflexão crítica na formação e atualização profissionais.

É relevante pensar que as repercussões psicossociais, políticas e midiáticas da atual pandemia da COVID-19 acentuaram, ao mesmo tempo, crenças sobre o valor e o mérito da produção e comunicação científicas, assim como o contrário, o sentimento de desconfiança sobre o papel da ciência, em geral. Compreender essa dicotomia é parte das tensões políticas, científicas e sociais que vivemos nessa crise.

A busca por compreender o que é o vírus Sars-CoV-2 e suas repercussões na saúde física e mental das populações provocou, desde o início da pandemia, uma procura incessante por evidências científicas sobre o processo infeccioso e seus efeitos. A expectativa é que essas evidências possam auxiliar não somente no entendimento epidemiológico-clínico da pandemia, mas especialmente nas decisões sobre políticas públicas e no gerenciamento da crise sanitária e econômico-social.

De fato, não há respostas definitivas ou certezas absolutas na ciência. Isso pode ser percebido, concomitantemente, como uma fraqueza ou atitude ética diante da "incomensurabilidade dos fatos", nas palavras de Kuhn (2011). Nesse sentido, a ciência é concebida como um empreendimento humano, com seus limites de observação e mensuração sobre aspectos da realidade.

Em função disso, a produção de conhecimentos científicos é dinâmica e, muitas vezes, difusa, pois contém várias perspectivas e possibilidades de interpretação. A busca de evidências, por sua vez, assinala um percurso racional, típico do empreendimento científico, baseado no compromisso de melhor se ater aos fatos e às suas consequências, revisando constantemente argumentos que possam aperfeiçoar a compreensão do que se pretende conhecer ou demonstrar.

Em tempos de incertezas, tal como a pandemia da COVID-19 revelou, a ciência se orienta como uma vela no escuro "em um mundo assombrado pelos demônios", utilizando uma metáfora de Sagan (2006), astrônomo conhecido por popularizar a ciência na mídia. Ou seja, o empreendimento científico tem por finalidade ampliar o conhecimento sobre a realidade, ainda que não se possa conhecê-la totalmente, valorizando o pensamento crítico em detrimento de dogmas ou superstições. E, divulgá-lo, é parte relevante do processo de validação de quais conhecimentos podem ser necessários e relevantes à sociedade.
O conhecimento é um fenômeno que deve ser disponibilizado às pessoas. Essa é a principal tarefa de todo cientista. E, em períodos em que se necessita acentuadamente de produtores e divulgadores da ciência para enfrentar os problemas e desafios sanitários e socioeconômicas, como é o caso da pandemia da COVID-19, publicações científicas de acesso aberto podem contribuir para a disponibilização de um dos maiores bens públicos: o conhecimento.

A rPOT se alinha a essa diretriz, tendo em vista que sua missão é difundir de forma ampla e responsável conhecimentos técnico-científicos e a promover reflexões críticas sobre fenômenos, fatos, problemas ou demandas que possam ser objeto de compreensão e intervenção por parte dos cientistas, professores e profissionais do campo da Psicologia das Organizações e do Trabalho.

Nesse contexto de forte crise humanitária, constata-se que as mudanças inesperadas e generalizadas nas condições de vida, trabalho e convivência social, provocados pela pandemia da COVID-19, impuseram desafios importantes ao mundo do trabalho e das organizações. A pandemia da COVID-19 pode durar potencialmente um longo período e seu impacto na ciência e na sociedade contemporâneas provavelmente será sentido, também, por um longo tempo.

A crise sanitária, o isolamento e o confinamento das pessoas, a necessidade de reorganização das condições de execução das atividades de trabalho, o aumento das taxas de desemprego e a precarização vida em sociedade produzirão um legado sem precedentes na manutenção da base dos empregos formais e informais, especialmente entre trabalhadores e empresas mais vulneráveis aos efeitos da crise econômica associada à pandemia (Cruz, et al, 2020). Os riscos à saúde física e mental podem ser exacerbados durante e após os períodos críticos da pandemia, contribuindo para o absenteísmo-doença e para a dificuldade de manutenção da sobrevivência e integridade pessoal e familiar (Usher, Durkin, \& Bhullar, 2020; Vindegaard, \& Benros, 2020).

Diante desse cenário, a rPOT mantém o seu interesse em receber contribuições científicas acerca dos impactos e mudanças no trabalho, na saúde e na gestão de processos organizacionais diante da situação da pandemia da COVID-19. Os artigos com contribuições empíricas nessa direção, uma vez aprovados pelas rotinas de avaliação da rPOT, serão priorizados para um número especial em 2021, ou em fluxo contínuo, conforme as demandas à revista.

Por fim, nos resta desejar que consigamos superar o mais rapidamente possível essa crise.

\section{Referências}

Cruz, R. M., Borges-Andrade, J. E., Moscon, D. C. B., Micheletto, M. R. D., Esteves, G. G. L., Delben, P. B., ... \& Carlotto, P. A. C. (2020). COVID-19: emergência e impactos na saúde e no trabalho. Revista Psicologia Organizações e Trabalho, 20(2), I-III. https://doi.org/10.17652/rpot/2020.2.editorial Kuhn, T. S. (2011). A estrutura das revoluções científicas. São Paulo: Perspectiva. 
Sagan, C. (2006). O mundo assombrado pelos demônios: a ciência vista como uma vela no escuro. São Paulo: Companhia das Letras.

Usher, K., Durkin, J., \& Bhullar, N. (2020). The COVID-19 pandemic and mental health impacts. International Journal of Mental Health Nursing, 29(3), 315. https://doi.org/10.1111/inm.12726

Vindegaard, N., \& Benros, M. E. (2020). COVID-19 pandemic and mental health consequences: Systematic review of the current evidence. Brain, behavior, and immunity, 89, 531-542. https://doi.org/10.1016/j.bbi.2020.05.048

Roberto Moraes Cruz

Editor-Chefe - Universidade Federal de Santa Catarina (UFSC), Brasil

Jairo Eduardo Borges-Andrade Editor Sênior - Universidade de Brasília (UnB), Brasil

Alexsandro Luiz De Andrade Editor Associado - Universidade Federal do Espírito Santo (UFES), Brasil

Daniela Campos Bahia Moscon

Editora Associada - Universidade Federal da Bahia (UFBA), Brasil

João Viseu

Editor Associado - Universidade do Algarve (UAlg), Portugal

Marcos Ricardo Datti Micheletto Editor Associado - Universidade Estadual Paulista "Júlio de Mesquita Filho” (UNESP), Brasil

Nádia Kienen

Editora Associada - Universidade Estadual de Londrina (UEL),

Brasil

Germano Gabriel Lima Esteves

Editor Júnior - Universidade de Rio Verde (UniRV), Brasil

Paola Barros Delben

Editora Júnior - Universidade Federal de Santa Catarina (UFSC),

Brasil

Maria Nivalda de Carvalho-Freitas Presidente da Associação Brasileira de Psicologia Organizacional e do Trabalho (SBPOT), Brasil 